\title{
AUTONOMIZACIÓN Y FUNCIONES DEL SUBCAMPO DE LA TRADUCCIÓN LITERARIA VASCA CONTEMPORÁNEA: UNA APROXIMACIÓN SOCIOLÓGICA
}

\author{
MiREN IBARLUZEA \\ Universidad del País Vasco-Euskal Herriko Unibertsitatea \\ miren.ibarluzea@ehu.eus \\ MARI JOSE OlazIREGI \\ Universidad del País Vasco-Euskal Herriko Unibertsitatea \\ mj.olaziregi@ehu.es
}

\begin{abstract}
RESUMEN: En el presente artículo trataremos de reflexionar en torno al proceso de autonomización del subcampo de la traducción literaria vasca, anotando algunas de las funciones que ha cumplido la traducción en la literatura vasca. Repasaremos la evolución vivida durante las últimas décadas por los agentes que componen el subcampo de la traducción literaria vasca. Partiremos de los momentos históricos que han condicionado el devenir de la traducción actual en Euskal Herria: la estandarización de la lengua vasca en 1968 y la aceptación de las diversas leyes de bilingüismo en la Euskal Herria peninsular. Completará nuestro análisis una breve reflexión sobre la presencia que la traducción ha tenido en la historiografía literaria vasca, además de un breve comentario en torno a la creciente representación del traductor/traductora en la ficción contemporánea vasca y un esbozo de los flujos de traducción del/al euskera de las últimas décadas.
\end{abstract}

PALABRAS CLAVE: literatura vasca; campo de la traducción literaria; funciones y representaciones de la traducción literaria

ABSTRACT: We will try to reflect on the autonomous process within the sub-field of Basque literary translation, noting some of the functions fulfilled by translation in Basque literature. Likewise, we will review the evolution experienced during recent decades by the agents who make up the sub-field of Basque liter-

\footnotetext{
${ }^{1}$ Este artículo se ha redactado en el marco de las actividades del grupo de investigación inscrito con el número IT 1047-16 y financiado por el Gobierno Vasco.
} 
ary translation. We will start from the historical moments that have conditioned the development of current translation in the Basque Country: the standardization of the Basque language in 1968 and the accepting of different laws on bilingualism in the peninsular Basque Country. Our analysis will finish up with a brief reflection on the presence of translation in Basque literary historiography, as well as a brief commentary on the growing representation of the translator in contemporary Basque fiction and an outline of the ebb and flow of translation from/to the Basque language in recent decades.

KEYWORDS: Basque Literature; Field of Literary Translation; Functions and Representation of Translation

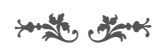

\section{INTRODUCCIÓN: HIPÓTESIS Y PUNTOS DE PARTIDA TEÓRICOS}

Este artículo no es un relato minucioso de la historia de la literatura vasca traducida de las últimas décadas, ni incluye un listado de traductores y traductoras exhaustivo; el presente artículo tampoco pretende recopilar todos los datos de los textos de literatura vasca traducidos a otras lenguas o los textos traducidos en lengua vasca; sí trata, en cambio, de reflexionar en torno al proceso de autonomización del subcampo de la traducción literaria vasca y su influencia en el campo de la literatura vasca.

Partimos de la asunción de que la traducción literaria conforma un subcampo de autonomía relativa dentro del campo de la literatura vasca. Pierre Bourdieu propone el concepto "campo" como un esquema básico de ordenamiento de las realidades sociales: es un espacio social, estructurado y estructurante, compuesto por instituciones, agentes y prácticas. El campo está estructurado en la medida en que existen normas y reglas explícitas o implícitas y se establecen relaciones lógicas entre agentes del campo y agentes exteriores (Vizcarra 2002). Bourdieu atribuye la autonomía de los campos o la creación de nuevos subcampos a) al aumento de consumidores potenciales por incremento de la pluralidad social; b) al aumento de productores y mediadores de los productos simbólicos (relacionado con la autonomía económica de los agentes); y c) a la creación de agencias de consagración propias al campo (1984: 112-115). Creemos que estas tres condiciones se cumplen en el ámbito de la traducción literaria vasca, y basándonos en los conceptos teóricos de P. Bourdieu, concebimos el subcampo de la traducción literaria vasca como un espacio dinámico, multidireccional y transnacional, de procedimientos complejos y tejido de redes de fuerzas interrelacionadas influyentes en otros campos e influidas, al mismo tiempo, por fuerzas externas de los (sub)campos con los que el subcampo que nos ocupa se interrelaciona.

A nuestro parecer, la teoría sociológica de P. Bourdieu dota a los estudios de traducción de conceptos sólidos para describir las condiciones culturales y 
sociales que influyen en el proceso traductológico y en el producto del subcampo, así como en las estructuras y en los productos de los campos interrelacionados con el subcampo. Creemos, además, que aplicando esta teoría se rebasan las clasificaciones deterministas y simplistas extraídas únicamente de descripciones sistémicas; así lo indican profesores como Munday (2008: 158-159) o Wolf (2007: 6-7). Munday menciona, por ejemplo, que mediante la aplicación de la metodología sistémica de Toury pasan desapercibidos algunos de los factores políticos e ideológicos como el estatus de la cultura del texto de origen, la posible promoción de la traducción desde la cultura de origen o del efecto que ejerce la literatura exportada en el sistema de la cultura de partida (2008: 115). Wolf, por su parte, defiende que poner el foco en las interrelaciones culturales y sociales ayuda a evitar puntos de vista deterministas y binarios y, subraya, también, que los agentes de un sistema no se encuentran aislados (2007: 6-7).

Por todo ello, consideraremos a lo largo de este artículo tanto la literatura traducida al euskera como la literatura creada en euskera traducida a otras lenguas, estimando que todos los procesos traductológicos forman parte del subcampo de la traducción literaria vasca, y que las traducciones en las dos direcciones (del y al euskera) influyen tanto en la estructura y en las influencias del subcampo de la traducción literaria vasca como en el campo más amplio en el que se integra ese subcampo, es decir, en el campo de la literatura vasca.

En la misma línea, consideramos el subcampo como un espacio transnacional (Heilbron y Sapiro 2002: 3-5), en el que destacan e influyen, en nuestro caso, sobre todo (pero no solamente) políticas culturales llevadas a cabo desde un espacio concreto: se trata del espacio de la Euskal Herria peninsular (Comunidad Autónoma Vasca y Comunidad Foral de Navarra), únicos territorios donde la lengua vasca es cooficial.

El eje geográfico está relacionado, a su vez, con un eje temporal inherente a ese espacio. Así, en cuanto a los límites temporales, son de marcada importancia en el proceso de autonomización del subcampo de la traducción literaria vasca los condicionantes históricos del devenir de la literatura y la traducción en euskera: la estandarización de la lengua vasca (1968), por un lado, y la promulgación de las diversas leyes de bilingüismo en la Euskal Herria peninsular (Comunidad Autónoma Vasca y Comunidad Foral de Navarra). Partimos, por lo tanto, de los momentos históricos en los que la literatura vasca ha ahondado en su proceso de autonomización (Lasagabaster 2007: 244-245), un proceso claramente condicionado, como decíamos, por la realidad histórico-social del País Vasco, en especial, la del inicio de la denominada era democrática en la Euskal Herria peninsular, a partir de 1975, el Decreto de Bilingüismo de 1982 en la Comunidad Autónoma Vasca y en 1986 en la Comunidad Foral de Navarra, y las consiguientes ayudas a la creación y edición en esa lengua establecieron las bases para que el proceso de autonomización de la literatura en lengua vasca fuera una realidad.

En lo que a la estructura de este artículo se refiere, articularemos nuestra reflexión en el marco de la sociología de la traducción y entenderemos la traducción como una actividad regulada por la sociedad y caracterizada por sus 
agentes, de modo que la actividad de la traducción consta de un valor social y comunicativo específico (Wolf 2007: 1). Las características y el valor social de la traducción se analizan, entonces, mediante la descripción de los autores de los textos, las agencias que se ocupan de la transferencia o las relaciones entre el texto y el público entre otros. Será, por tanto, la descripción de las características y los valores de la actividad social de la traducción la que constituirá el eje del presente artículo. Cuestiones referentes a la posición de los agentes, las fuerzas de poder, las actitudes cognitivas y sociales, o las implicaciones y funciones que construyen el subcampo que nos ocupa conformarán los contenidos de los párrafos que siguen, en base a dos ejes principales: a) el proceso de autonomización del subcampo de la traducción literaria vasca y b) las funciones del subcampo de la traducción en el campo de la literatura vasca. Repasaremos, por un lado, la evolución de los agentes que componen el subcampo de la traducción literaria vasca, tratando de describir algunas de las relaciones y redes que influyen en la estructura del subcampo y en su aceptación y representación; y, por otro lado, intentaremos visibilizar y presentar algunas de las influencias ideológicas, económicas y culturales de la traducción literaria vasca (tanto la importada como la exportada).

\section{LA AUTONOMIZACIÓN DEL SUBCAMPO DE LA TRADUCCIÓN LITERARIA VASCA}

Gisele Sapiro (2010, 2014), discípula de Bourdieu, propone tres niveles de influencia (y análisis) del proceso de la autonomización de un (sub)campo. El primer nivel de influencia es el relativo a las condiciones materiales de la producción y la circulación de las obras, y se manifiesta en el rol social y en la ética profesional, en las instituciones y en las estructuras del campo. En un segundo nivel se encuentran las disposiciones de los artistas y literatos, en este caso, las disposiciones de los traductores y los escritores. Por último, el tercer nivel de estudio de la influencia del (sub)campo es el de las condiciones de recepción y proyección del (sub)campo. Según Sapiro, la autonomía del (sub)campo (en este caso, el subcampo de la traducción literaria) está ligada a la constitución de un cuerpo de especialistas que reivindican el monopolio del dominio del (sub) campo y el monopolio de regulación de las condiciones de acceso a la actividad; además, la autonomización del (sub)campo también se asienta en la inscripción de las referencias a la historia del (sub)campo: es decir, a la creación de una historia propia del campo (Sapiro 2014: 34-107).

En las líneas que siguen, trataremos de ilustrar cómo se percibe el proceso de autonomización del subcampo de la traducción literaria vasca en los tres niveles propuestos por Sapiro.

2.1 Condiciones de producción y circulación: estructuración del subcampo de la traducción literaria

El primero de los niveles de influencia del (sub)campo es su propia estructuración (las condiciones de circulación, las instituciones, las referencias al 
propio (sub)campo y el nivel de profesionalización). Como veremos a continuación, la estructura del subcampo de la traducción literaria vasca tiende a ser cada vez más específica, aunque aún se encuentra fuertemente condicionada por los campos en los que se inscribe, como son el del mercado de los productos lingüísticos o el de la literatura. La traducción ha sido el eje central del devenir histórico de los textos vascos, incluso más allá del siglo xvIII. El subcampo de la traducción literaria vasca es una nueva entidad social, fruto de la evolución y dinámicas de otros campos, y su proceso de autonomización, del mismo modo que ocurrió en el caso del campo de la literatura vasca (Lasagabaster 2007: 237248), comienza con la llegada de la era democrática en la Euskadi peninsular a partir de 1975, unida, como decíamos anteriormente, a la cooficialidad del euskera en la Comunidad Autónoma Vasca y en la Comunidad Foral de Navarra. La obligatoriedad de la lengua vasca en la educación, en la administración y en los medios de comunicación incrementó, obviamente, las necesidades de traducción en la sociedad y las posibilidades de trabajo para los traductores. Durante los primeros años, fueron sobre todo escritores, lingüistas, filólogos, profesores, periodistas... quienes se dedicaron a las labores de traducción (en muchos casos, de manera desinteresada y militante). Pero, con el paso del tiempo, los traductores sintieron la necesidad de una formación específica, y en ese contexto se creó en 1987 la asociación EIZIE (Asociación de Traductores, Correctores, e Intérpretes de Lengua Vasca) y apareció también la primera escuela de traducción: "Martuteneko eskola" (=Escuela de Martutene), en 1980. Tras varios años de andadura en la formación no oficial, cerró sus puertas y los futuros profesionales de la traducción pudieron formarse en másteres como los que se impartieron en la Universidad del País Vasco-Euskal Herriko Unibertsitatea, o en la Universidad de Deusto y, más adelante, en el año 2000, se instauró la licenciatura de Traducción e Interpretación en la Facultad de Letras de la Universidad del País Vasco de Vitoria-Gasteiz, hoy convertida en estudios de grado.

La especialización en el subcampo se refleja tanto en la paulatina profesionalización del traductor como en el mundo editorial: no cabe duda de que muchas de las traducciones que se realizaron a principios de la década de 1980 para responder a la demanda del momento no cumplieron el nivel de calidad lingüística y editorial exigible (de ahí, también, la mala fama que han tenido las traducciones literarias vascas durante años), pero los años y la normalización de la cultura y de la lengua, así como la profesionalización y especialización de los traductores, no han avanzado en vano: hoy por hoy podemos asegurar que la calidad de las traducciones ha mejorado considerablemente, y que la contribución de los traductores literarios al desarrollo de la lengua literaria vasca es generalmente subrayada por los diversos agentes del campo literario (Behinola 2009: 7-13; Olaziregi 2012: 160; Ibarluzea 2015a: 69).

Además, durante los últimos años se han creado editoriales y colecciones específicas dedicadas exclusivamente a la publicación de traducciones. Así, citaremos, por ejemplo, la recién creada editorial Pasazaite, que publica "libros de importación" como señalan en su página web, o la colección Munduko Poesía Kaierak (=Cuadernos de Poesía del Mundo) de la editorial Susa, o la colección 
Batera (=Juntos) de la editorial Erein. Todas ellas serían ejemplo, según indica Luc Boltanski (1975: 37), del fenómeno de la acumulación sistémica selectiva o de la creación de productos específicos de un (sub)campo.

En cuanto a la traducción inversa, la acumulación sistémica selectiva también es cada vez mayor: las colecciones y la cantidad de obras de literatura vasca traducidas a otras lenguas aumentan; pueden citarse, entre otros, la "Biblioteca vasca bilingüe" de la Editorial Atenea, la colección "Basque Literature Series" del Center for Basque Studies de la Universidad de Nevada (Reno) (2004-), o el espacio dedicado a la literatura vasca en colecciones como "collane m30" (colección de la editorial Gran Via edizioni que reúne algunas obras de la "narrativa de la España plural" según su página web), o la editorial eslovena Malinc; además, asociaciones como la vasco-alemana Euskalema también apuntalan el ámbito de la literatura vasca traducida. En cualquier caso, parece que la tendencia a exportar literatura vasca aumenta y los traductores especializados en traducir literatura vasca (muchos de ellos traducen directamente del euskera) también son cada vez más, según datos aportados por el Instituto Vasco Etxepare.

La traducción literaria también forma parte del mercado existente en torno a la lengua, y prueba de su desarrollo y cooperación es, por ejemplo, la red de agentes "Langune". Se trata de una asociación empresarial del sector de las industrias de la lengua en Euskal Herria, nacida en el año 2010 y que agrupa a más de 35 entidades de los campos de la traducción, de la enseñanza y de las tecnologías de la lengua. La mencionada EIZIE, junto a la Universidad del País Vasco, o la Fundación Elhuyar, líder empresarial en servicios de la lengua, es uno de los muchos entes asociados a Langune.

Asimismo, las relaciones interinstitucionales también cruzan fronteras: la asociación EIZIE es también miembro de CEATL (asociación que reagrupa diversas asociaciones de traductores literarios europeos). Este es un buen ejemplo del tejido institucional y cooperativo del subcampo de la traducción literaria vasca, un tejido con el que se busca legitimar la actividad, apropiarse de espacios de negociación propios y tomar decisiones sobre temas relacionados principalmente con las políticas de mercado y con las condiciones laborales, por citar algunos ejemplos.

Desde el año 2000, el Gobierno Vasco ha impulsado ayudas y bolsas para la traducción de obras en euskera a otras lenguas. Hoy por hoy, es el Instituto Vasco Etxepare (http://www.etxepare.eus) para la promoción y difusión de la lengua y cultura vascas, quien promueve las políticas de mercado y las traducciones a otras lenguas mediante publicaciones de catálogos, convocatorias de ayudas, becas y estancias para editoriales, autores y traductores y mediante su presencia en ferias internacionales; el portal basqueliterature.com integrado en la página web del instituto también es otro de los proyectos en este ámbito. Todas esas actuaciones acentúan la autonomización y la especialización del subcampo de la traducción literaria vasca y sus productos específicos, ya que la irrupción en el panorama internacional de la promoción y difusión de la literatura vasca por parte del Instituto Vasco Etxepare a partir de 2011 ha permitido abrir otras vías de visibilización de la literatura vasca; en efecto, si bien es verdad que el Gobier- 
no Vasco comenzó anteriormente a dar ayudas a la traducción de obras literarias vascas a otras lenguas, no se incluían convocatorias de ayudas públicas para la presentación de las traducciones en festivales y ferias internacionales, o colaboraciones internacionales con redes o instituciones que se dedican a la formación y difusión de literatura traducida.

Crecen también los proyectos de instauración de referencias históricas inherentes al subcampo y, por ejemplo, la asociación EIZIE alberga en su página web un inventario de traducciones literarias y traductores llamado "Nor da nor" (=Quién es quién; http://nordanor.eus/). Actualmente pueden consultarse datos sobre las traducciones realizadas desde o al euskera de diversos géneros, tales como la literatura para adultos y la literatura infantil y juvenil. En cuanto a los traductores y traductoras, aparecen listados todos los miembros de la asociación, sean traductores literarios o traductores generalistas, pero la centralidad que la traducción literaria tiene en las bases de datos y proyectos de la asociación es manifiesta. Sea colaborando con la promoción internacional de los traductores literarios vascos a través del Instituto Vasco Etxepare (http//www.etxepare.net) sea impulsando la colección "Literatura Unibertsala" gracias al convenio firmado con el Gobierno Vasco, la traducción literaria ha conformado, desde su origen, el eje central de la actividad anual de la asociación. Dicha centralidad se manifiesta, como puede comprobarse en la propia web de la asociación (http//www.eizie. eus), en el peso (económico, estratégico, simbólico) que la colección de literatura traducida ha tenido y tiene en la asociación.

\subsection{Disposiciones de traductores y escritores vascos}

La reestructuración de los agentes del subcampo de la traducción literaria y su profesionalización se expresa también en las disposiciones y posicionamientos de los agentes que participan en él. Es lo que hemos tratado de indagar al preguntarnos por la percepción que tienen los traductores de sí mismos, o por las tensiones y colaboraciones que establecen con los escritores.

En este sentido, podríamos afirmar que la imagen del traductor literario y de la literatura traducida es cada vez más positiva, aunque parece que al traductor le cuesta todavía hacerse visible; ocurre así, por ejemplo, en los paratextos de la citada colección "Literatura Unibertsala". En ella, es el propio traductor de la obra el que escribe el prólogo de la misma. Tras haber analizado 152 prefacios de dicha colección (Ibarluzea 2014), podemos constatar que el traductor entra en escena como cónsul de la literatura que se importa, explica la biografía del autor y su obra, realiza en los prefacios una tarea contextualizadora de la obra, pero pocas veces comenta aspectos ligados a la propia traducción. La reconocida traductora Begoña Montorio apuntaba en la presentación del citado estudio que se trata de un fenómeno normal, ya que hasta el momento el traductor ha interiorizado la idea de que no debía dejar rastro en el texto o en la obra traducida (Ibarluzea 2014: 708).

En cuanto a la percepción que los escritores tienen de la traducción literaria y la labor de los traductores, la imagen positiva sobre el rol de los traductores 
parece hacerse cada vez más visible tanto en las reflexiones públicas de los creadores contemporáneos vascos como en las diversas formas en que representan a los traductores en sus obras de ficción. Podríamos decir que la evolución del subcampo de la traducción literaria vasca ha influido tanto en las prácticas de creación y traducción de los escritores en lengua vasca como en su poética, y que el cambio de la imagen social del traductor se ha visto reflejado también en la irrupción de la imagen del traductor como personaje de ficción y en la evolución de la imagen del "traductor traidor" en sus obras. Es importante constatar que varios escritores vascos han plasmado su experiencia traductológica en sus obras de ficción, y en muchos casos parodian experiencias relacionadas con la traducción, como en la novela Katebegi galdua de Jon Alonso (Trad.: El eslabón perdido, 2003), o en el relato "Itzulpengintza" (=Traducción) de Iban Zaldua en Idazten ari dela idazten duen idazlea (=El escritor que escribe mientras escribe, Elkar 2012). Los traductores ficcionales, además de estar situados en entornos geográficos cada vez más cercanos (en relación al País Vasco), también parecen ocupar un lugar cada vez más central en la trama: por ejemplo, pasan de ser narradores a ser personajes principales. Ocurre así en Twist (2011) de Harkaitz Cano, en Mussche (2012; traducida al español con el título Lo que mueve el mundo) de Kirmen Uribe, o en Martutene (2014), de Ramon Saizarbitoria. Además, la profesionalización de los traductores parece reflejarse también en la caracterización de los traductores ficcionales, al igual que ocurre en el subcampo de la traducción literaria vasca; sucede así en Martutene: Julia, personaje principal de la novela, es traductora profesional (Ibarluzea 2015a).

Los autores contemporáneos vascos perciben la traducción literaria como una realidad muy cercana; la traducción literaria ha sido una actividad creativa en casos como el de Joseba Sarrionandia. Tal y como demostró la tesis de Aiora Jaka (2012), para Sarrionandia traducir literatura es crear (tradutore=creatore), y esta concepción postmoderna de la traducción se ha visto plasmada en su obra. Títulos suyos como Izkiriaturik aurkitu ditudan ene poemak (=Poemas que encontré escritos), libro que incluye las traducciones del propio Sarrionandia de maestros universales, son absolutamente reveladores. Para otros autores contemporáneos, la traducción literaria ha sido una actividad muy común ligada a su actividad literaria y han realizado, en la mayoría de los casos, traducciones de textos de otros autores además de autotraducciones (Ibarluzea 2005a); sin embargo, entre los autores más jóvenes se aprecia una tendencia hacia la clara separación entre la creación y la traducción literaria, y cada vez son más los que prefieren no autotraducirse y centrarse únicamente en la labor creativa: tal es el caso, por ejemplo, de autores canónicos como Harkaitz Cano o Kirmen Uribe (idem).

En cuanto a las disposiciones de la lectura y uso de traducciones en euskera entre los escritores vascos, podemos constatar que algunos de los escritores vascos reconocen haber leído por primera vez a ciertos autores universales a través de traducciones realizadas al euskera:

Sí, claro que leo traducciones en euskera. Es más, he descubierto algunos autores mediante traducciones en euskera, por ejemplo a Zweig. Desgraciadamen- 
te, he tenido que leer seguramente todas las obras importantes en la formación de cualquier persona en castellano, en el 75 no existía Cortazar en euskera, ¿se entiende lo que quiero decir, verdad?. (Alonso 2013) ${ }^{2}$

Además, los escritores vascos contemporáneos aplauden la labor de los traductores vascos en cuanto al aporte de nuevos registros lingüísticos y estilísticos (Ibarluzea 2015a: 68-72), y hacen uso de las obras traducidas al euskera como modelos estilísticos y de escritura:

Además, lo digo de verdad, las traducciones han influido en la lengua y en el estilo de los escritores de nuestra generación; mencionaría por ejemplo a Cano. La traducción ha ayudado a embellecer la lengua vasca y a acrecentar su nivel. Ha influido en nuestro estilo, escribiríamos de manera más áspera. Un traductor ofrece muchísimas soluciones para que uno mismo pueda escribir después. Aprendes a estructurar las frases, las frases largas, el ritmo... todo eso te lo enseña un traductor. Si no, es muy difícil. (Uribe 2013) ${ }^{3}$

Por último, cabe comentar respecto a la traducción de las obras de autores vascos a otras lenguas, que los autores vascos las perciben como "un premio" o reconocimiento (Ibarluzea 2015a: 66-67), y, además, es para ellos un paso hacia la profesionalización de su actividad literaria como apunta Olaziregi: "Only a very limited percentage of writers (not even 10 percent of Basque-language writers) live off writing alone, and they need to get translated into other languages to achieve financial independence" (2012: 161).

\subsection{Recepción de la traducción literaria vasca}

El tercer nivel de influencia del (sub)campo es el relativo a la recepción, y se manifiesta, por ejemplo, en el juicio estético y social. A continuación, trataremos de dibujar algunas tendencias al respecto y, para ello, analizaremos la crítica de obras literarias traducidas al euskera y la presencia que la literatura traducida tiene en los clubes de lectura en euskera; además mencionaremos la creciente aceptación de literatura vasca traducida en el extranjero.

Tras el análisis de 511 críticas publicadas en diversos medios de comunicación (escritos y digitales) entre los años 2000 y 2009 (Ibarluzea 2011), podemos concluir que los comentarios críticos sobre las obras literarias traducidas en lengua vasca están muy ligados a la normalización lingüística y al fomento de la literatura traducida en euskera: se intenta, en la mayoría de los casos, subrayar el elevado nivel lingüístico, el buen uso del idioma y la buena legibilidad de las obras traducidas. Los comentarios sobre las traducciones se centran, en su gran mayoría, no tanto en el proceso de traducción o en las aportaciones literarias de las obras, sino en la lengua en sí. Del mencionado análisis deducimos que se

2 Respuesta para Ibarluzea a formulario en euskera no publicado (2015a; traducción de las autoras).

${ }^{3}$ Entrevista personal inédita en euskera de Ibarluzea (2015a; traducción de las autoras). 
otorga gran importancia al crédito de los autores, los traductores y agentes; esto es, se subraya, ante todo, su profesionalidad, su trayectoria y su experiencia, y se destaca la importancia de haber traducido las obras en cuestión. Puede tratarse, en nuestra opinión, de un intento de legitimización de la actividad del traductor y de sus productos en un entorno en el que cuesta todavía aceptar y consumir literatura traducida. También es preciso destacar que, en cuanto al número de críticas publicadas, se percibe una tendencia al alza y que la literatura traducida ocupa cada vez más lugar en las páginas de nuestros periódicos, revistas o blogs en internet (Ibarluzea 2011: 87-89).

En lo referente a la recepción lectora de las obras traducidas al euskera, parece ser que la aceptación y lectura de éstas es cada vez mayor; aun así, el lugar que ocupan las traducciones literarias en euskera respecto a las creaciones en euskera entre las lecturas de los clubs de lectores es reducido. Basándonos en los datos de las obras que se leen en los clubs de lectura del País Vasco, llegamos a la conclusión de que, como tendencia general, la lectura de obras escritas originariamente en euskera ocupa el 70,7 \% del total de lecturas propuestas (Arrula 2013). Además, Iban Zaldua, escritor y moderador de uno de los clubs de lectura más activos, el de Vitoria-Gasteiz, apunta que en las sesiones en las que la obra a analizar y comentar en grupo es una traducción, el número de participantes disminuye un 40 \%. ${ }^{4}$ Zaldua afirma que este fenómeno puede deberse al hecho de que el autor no suele estar presente en la sesión (sucede así normalmente con las demás obras, los creadores vascos acuden a menudo a las sesiones de los clubs de lectura), pero también a aspectos como la realidad diglósica del País Vasco. En opinión de Zaldua, los lectores todavía no se han habituado a leer cierto tipo de registros en euskera, y algunos autores en lengua vasca tienden a simplificar los registros, lo que convierte a sus obras en textos de lectura fácil frente al nivel y registro lingüístico más elevado de obras universales traducidas. ${ }^{5}$

Por su parte, acerca de la recepción de la literatura vasca en otras lenguas, no nos constan análisis o investigaciones concretas al respecto (a excepción de la tesis doctoral de Olaziregi sobre la recepción de las obras de Bernardo Atxaga), pero, en cualquier caso, podemos observar tendencias al alza en cuanto a la buena aceptación de la literatura vasca en el extranjero, no solo constatables en la demanda, cada vez mayor, de traducciones de literatura vasca a otras lenguas sino también en la aprobación y valoración de esas obras mediante críticas positivas, tal y como ocurrió en el caso de la antología de poesía vasca editada por Mari Jose Olaziregi y traducida del euskera al inglés por Amaia Gabantxo: Six Basque Poets (Arc Publishers, 2006), ${ }^{6}$ o en premios como el del Premio a la Mejor Traducción al Japonés 2016 a Nami Kaneko por su traducción de la novela Mussche, de Kirmen Uribe, por citar solo dos ejemplos.

\footnotetext{
${ }^{4}$ Comunicación personal del autor.

${ }^{5}$ Comunicación personal del autor.

${ }^{6}$ Se pueden consultar algunas de las críticas en la página web de la editorial Arc. Véase: < https:// http//www.arcpublications.co.uk/books/mari-jose-olaziregi-six-basque-poets-359> (consultado el 29.05.2016).
} 
3. FUnCIONES DE LA TRADUCCIÓN LITERARIA VASCA: FUNCIÓN IDEOLÓGICA, ECONÓMICA Y CULTURAL

Sapiro subraya que la traducción es, ante todo, una práctica social que cumple diversas funciones. Son las tres funciones que ella destaca, las ideológicas, económicas y culturales (2014: 94), las que analizaremos, en las líneas que siguen, a propósito de la literatura vasca contemporánea.

La primera de ellas, la función ideológica, responde, según Sapiro, a la voluntad de expandir un modo de ver el mundo y, en este sentido, la circulación de obras literarias puede estar condicionada por factores externos, tales como, por ejemplo, los regímenes autoritarios. Es por ello que Sapiro habla de posibles tipos de circulación de obras traducidas, tanto oficiales como no oficiales (2014: 94-95). Pero además, la traducción puede influir en la obra original, e incluso llegar a cambiar su función original; según Rubio Tobar, la traducción puede llegar a mostrar aspectos en ocasiones invisibles en el texto de partida (2013: 123). Y es que la traducción es un acto político, una herramienta de construcción lingüística, identitaria y cultural, como bien apunta Venuti: tanto la selección de las obras a traducir como las estrategias discursivas para traducirlas apoyan la formación de identidades nacionales (2013: 119).

El análisis del uso de la traducción como herramienta ideológica es también interesante en campos literarios como el vasco y trataremos de visibilizar ese uso en las líneas que siguen. Jesús María Lasagabaster (2002) subrayó el hecho de que la realidad literaria vasca es plurilingüe y plurisistémica (2002) y es precisamente esta interesante realidad la que se ha convertido en foco del debate historiográfico literario vasco actual (Olaziregi 2012: 7-12; Manterola 2014: 40-43), no solo por el intento de superar un planteamiento monolingüe y excluyente de las historias de la literatura vasca, sino por el hecho de aceptar la importancia que la traducción literaria tiene también como estrategia de acercamiento e intercambio entre las literaturas vascas.

En el caso de la literatura vasca es, tal y como hemos afirmado anteriormente, a partir de mediados del siglo xx cuando la literatura escrita en euskera ha avanzado hacia un claro proceso de autonomización (Olaziregi 2012: 7), y uno de los anhelos ha sido ampliar el capital y el estatus literario de los textos vascos mediante la traducción; de ahí el gran número de traducciones al euskera de periodos concretos de la historia literaria vasca, tal y como podía esperarse de sistemas literarios jóvenes, minorizados o en proceso de cambio (Jaka 2005). Pero, hoy por hoy, según datos de Santana (2015), el porcentaje de traducciones en lengua vasca (durante el periodo 2003-2009) es del 22.2\%; y el porcentaje de traducciones en español (durante el mismo periodo) es del 36.3\%. El dato es interesante en tanto en cuanto la literatura española ocupa frente a las demás literaturas ibéricas una situación hegemónica y, a nuestro entender, lo interesante en este caso es revisar no tanto el porcentaje de traducciones sino los tipos de procesos, de agentes y de relaciones que tejen y estructuran la constitución y las dinámicas de cada campo literario y de cada subcampo de traducción literaria. 
En cuanto a la traducción del euskera a otras lenguas, la traducción cumple, también en ese caso, una función ideológica clara, y es que, como nos lo recordó Casanova, más allá de la naturalización (en el sentido de cambio de nacionalidad) implica una littérarisation o la propia reafirmación como literatura, es decir, la construcción de capital literario propio ante instituciones legitimadoras (2004: 133); se trata de una necesidad, obviamente, que la literatura vasca no comparte con las literaturas centrales anglosajonas. El catálogo fruto de la tesis de Manterola, ELI, que incluye obras de literatura vasca traducida (http//www. ehu.es/ehg/eli/), ${ }^{7}$ resulta un buen punto de partida para analizar la evolución de la traducción de textos literarios vascos escritos en euskera y traducidos a otras lenguas, por cuanto visibiliza, por ejemplo, cuáles son las lenguas y mercados "meta" de esa literatura, dato que además de confirmar la aceptación y visibilización o no de la literatura vasca en algunos mercados, también puede revelar afinidades o decisiones estratégicas adoptadas por instituciones u organismos nacionales, estatales y extranjeros a la hora de hacer uso ideológico de las obras traducidas. Con un total de 480 títulos traducidos a un total de 38 lenguas hasta el año 2010, la literatura vasca presenta una realidad desigual respecto a las lenguas meta y al impacto global de los 161 autores euskaldunes traducidos. Las traducciones al castellano constituyen casi la mitad de toda la producción, clara muestra de la dependencia del sistema literario vasco del sistema español (Manterola 2014: 241). El catalán y el inglés son, seguidos por el gallego, las siguientes lenguas meta más populares. Solo el $46,66 \%$ de los libros analizados han sido traducidos directamente del euskera (Manterola 2014: 242), y la autotraducción (al castellano) y la traducción alógrafa son similares porcentualmente. Las distancias que marca Bernardo Atxaga respecto al resto de autores vascos son todavía importantes en cuanto a la traducción de sus obras. Un total de 35 títulos suyos han sido traducidos a un total de 31 lenguas, y Obabakoak (1988) supuso, sin duda, el inicio de una nueva era en la literatura vasca (Olaziregi 2005: 61). La obra dio visibilidad al autor a nivel global y lo canonizó, tanto en el sistema literario vasco como en el español, a raíz, sobre todo, de la obtención del Premio Nacional de Narrativa de 1989. La posición central de Atxaga en el actual sistema literario vasco ha corrido paralela a su canonización en el sistema interliterario ibérico. Como afirmó el profesor Mario Santana (2009: 216), de los 121 libros de narrativa que habían sido galardonados con el Premio de la Crítica entre 1976 y 2009, El hijo del acordeonista de Atxaga fue el primer libro traducido a todas las lenguas oficiales del estado español. El hecho resulta llamativo porque hablamos de un premio creado para impulsar las relaciones entre las literaturas de las cuatro lenguas del Estado. Como afirma Santana (2009: 216):

The lack of translations from Spanish points to the peculiarities of power relations between the languages of Spain. In the international book economy "asymmetry in translation" is the rule: minority literary systems tend to be overflowed with translations from dominant languages, and viceversa, translations into dominant systems is usually of little significance. (Santana 2009: 216)

${ }^{7}$ Catálogo ahora insertado en el anteriormente citado Nor da Nor. 
Santana vuelve a insistir, en artículos posteriores (2012, 2015), en la importancia que tiene el análisis de los diversos grados de dependencia, interferencia o autonomía sistémica entre las literaturas peninsulares. Así, las literaturas en gallego y euskera parecen depender en gran medida de la mediación del castellano para la importación de literatura extranjera, así como del resto de literaturas peninsulares (2012: 247), mientras que en el caso del catalán, esa mediación parece ser menos importante, aunque, dada la coexistencia con la castellana, cabe suponer que existe un alto grado de interferencia asimétrica entre ambas literaturas. La interferencia también se constata en investigaciones como la de Zubillaga (2014) quien analiza las traducciones de literatura infantil y juvenil traducidas del alemán al euskera haciendo notar que aunque las traducciones directas hayan ascendido en número aún se realizan muchísimas traducciones indirectas y que las interferencias también se hacen notar a nivel lingüístico.

La interdependencia de los campos literarios que nos ocupan en este caso ha tenido como consecuencia usos ideológicos concretos en cuanto a los procesos, las presentaciones y la visibilización de las traducciones realizadas del euskera. Analizaremos a continuación, las dos tendencias mayores en ese sentido: la invisibilización de la literatura vasca traducida pasando por el campo literario español y el intento de contrarrestar ese uso ideológico mediante estrategias (también de carácter ideológico) impulsadas desde dentro del campo de la literatura vasca.

Por un lado, si analizamos la página web < http//www.españaescultura. es > del Ministerio Español de Cultura, una página que presenta a los creadores y la oferta cultural del ámbito estatal, y nos centramos en la sección "Escritores", nos damos cuenta de que entre los 406 autores listados, solo cinco de los del total de unos 25 escritores y artistas vascos seleccionados escriben en euskera; es decir, un 1,2\% del total de creadores incluidos en la página web. Se trata de un dato sorprendente por cuanto hoy por hoy existe un colectivo de 300 autores que escriben en euskera y que, además, muchos de sus textos están traducidos al español. Pero si la invisibilidad de los escritores en lengua vasca es evidente, al menos, a ojos de la mencionada página web del Ministerio, no lo es menos la falta de reconocimiento o aceptación de la lengua, el euskera, en el caso de los autores vascos canonizados. Es revelador que cuanto más canónico es un escritor en lengua vasca en el sistema literario español, más invisible se vuelve la lengua en que escribe originalmente sus textos. El caso del escritor Bernardo Atxaga es, también en este sentido, particularmente revelador. Como apunta la profesora Elena Delgado (2014: 87), la citada página web del Ministerio no menciona el hecho de que escriba en lengua vasca. Lo mismo ocurre en el caso de los créditos de algunas de sus traducciones al español. Siguiendo con Atxaga, resulta interesante comparar su recepción en el ámbito español con países como el Reino Unido, donde su obra también ha sido muy bien recibida (Olaziregi 2005: 56-73). Más recientemente, el premio Marsh Award for Children's Literature in Translation, otorgado a la aclamadísima traductora del español al inglés y del portugués al inglés, Margaret Jull Costa, por su traducción de The Adventures of Shola, no ha hecho más que consolidar una trayectoria marcada por las diversas 
visitas del autor vasco al Edinburgh International Book Fair: su inclusión en las listas de los mejores libros del año (p.e. el listado del periódico Independent en 2013), su nominación como finalista del 2012 TLS Translation Prize por su Seven Houses in France, su inclusión por Publishers Weekly entre las 20 mejores novelas del año, etc.; son pruebas del excelente tándem que forman Atxaga y Jull Costa en el mercado anglosajón. Pero la pregunta es: ¿Cómo es percibida la obra del autor en el Reino Unido? ¿Como un autor vasco, español, europeo...? Ese tipo de preguntas no resultan excesivamente sorprendentes en el contexto de la proyección internacional de un escritor en lengua minoritaria, pero que, sin duda, sorprenderían si fueran realizadas a propósito de un escritor en lengua hegemónica. La respuesta a la anterior pregunta requeriría, sin duda, un análisis más exhaustivo de la evolución de la recepción de su obra.

Por otro lado, podríamos también recalar otros modos de hacer que, promovidos desde dentro del campo literario vasco, tratan de compensar la tendencia anteriormente citada de invisibilizar la traducción de las obras del euskera (y así también su origen vasco): se trata de estrategias que intentan reforzar proyectos de "territorialización" por medio de la creación de colecciones específicas (por ejemplo, el ya citado Basque Literature Series del Center for Basque Studies de la University of Nevada, en Reno) o por políticas de presentación y difusión de algunos títulos traducidos a las diversas lenguas peninsulares publicándolos de manera simultanea en diferentes puntos de la geografía española, o la traducción al euskera de títulos que no están traducidos al castellano, etc. Como decíamos en el apartado anterior, la irrupción en el panorama internacional del Instituto Vasco Etxepare ha permitido abrir otras vías de visibilización de la literatura vasca más allá del impacto canonizador del Premio Nacional de Literatura en España. Con una media de 20 traducciones financiadas anualmente, y una partida de bolsas de viaje para que escritores, traductores o editores promocionen la literatura vasca traducida en festivales, ferias (Guadalajara, Frankfurt, Gotemburgo, Liber...), jornadas o presentaciones, autores centrales en el sistema literario vasco tales como Harkaitz Cano, Arantxa Urretabizkaia, Iban Zaldua, Rikardo Arregi, Miren Agur Meabe o Mariasun Landa han incrementado su presencia en catálogos literarios internacionales. Es reseñable, por citar solo un ejemplo, el interés que, por ejemplo, ha generado la mencionada novela Twist (2013) de Harkaitz Cano. Se trata de una obra que ahonda en nuestro conflictivo pasado histórico, más concretamente, en los dramáticos acontecimientos que se vivieron durante la guerra sucia a ETA. La novela se tradujo al español en 2013 (Seix Barral), pero sus traducciones al inglés (Graywolf, traducida por Amaia Gabantxo), búlgaro (Small Station Press, traducida por Ventseslav Stefanov Nikolov) y serbio (Mandala, traducido por Sandra Nešović) están previstas para este año 2016. Twist es una novela interesante, además, porque, al igual que otras publicadas recientemente, incluye un personaje traductor cuyo rol ficcional es crucial en la obra, y marca un cambio en cuanto a la evolución de la imagen del traductor traidor en la literatura vasca: en este caso el traidor es el autor (Ibarluzea 2015a). Ligada a la función ideológica de la traducción y al intento de hacer visible una identidad lingüística y cultural, la territorialización se maximiza 
cuando se subraya la supuesta insularidad de la literatura vasca. La "isla" es uno de los principales geo-mitemas utilizados para presentar la literatura vasca fuera de sus fronteras. Al hilo de lo afirmado por Olaziregi en su estudio de la recepción de Obabakoak de Bernardo Atxaga (2005: 56-74), se puede constatar que la traducción de la obra sirvió para visibilizar a nivel global la existencia de una literatura vasca y superar esa supuesta insularidad apuntada reiteradamente por escritores vascos, insularidad que Domínguez compara acertadamente con la importancia que el concepto de "lengua isla" ha tenido entre estudiosos vascos (2010: 109). De hecho, Domínguez apunta el peso que tiene la limitación geográfica que establece el artículo $3^{\circ}$ de la Constitución española 1978, por cuanto el español es la lengua oficial del estado, y las otras lenguas peninsulares oficiales lo son únicamente en su ámbito geográfico (2010: 110). Dicha política lingüística y el hecho de que la proyección internacional de la literatura vasca se haya realizado, como en el caso paradigmático de Atxaga, vía la castellanización de su obra son, para Domínguez, las dos caras de la misma moneda (Domínguez 2010: 110). Quizás el dato más llamativo de la última década haya sido la evolución que las traducciones de la literatura vasca a otras lenguas han tenido. Aunque faltan estudios pormenorizados de las causas de esta tendencia, lo cierto es que la última década ha conocido un claro incremento de traducciones realizadas directamente del euskera a otras lenguas, que a nuestro entender, no es sino una muestra del carácter ideológico ligado a la importancia que agentes y académicos internacionales están dando a la necesidad de hacer visibles las culturas y literaturas llamadas menores/minoritarias. La obra del escritor Kirmen Uribe es reseñable en este sentido pues, de las 15 lenguas a las que Bilbao New York Bilbao está traducida, 7 se han realizado directamente del euskera. Seguramente, programas como el mencionado "Itzultzaile berriak" fomentado por instituciones públicas vascas como Etxepare Euskal Institutua con la intención de formar traductores internacionales en lengua vasca, habrán influido en esta realidad que evita la obligada castellanización de la literatura escrita en lengua vasca para su promoción internacional. Por lo tanto, podemos confirmar que, al igual que apunta Santana (2015), las traducciones vascas pueden ser instrumentos de función ideológica tanto en favor del desplazamiento o silencio de la diferencia como en favor de preservar y hacer visible la diferencia.

Además de esas dos tendencias generales en cuanto a la función ideológica de la traducción literaria se refiere, la traducción literaria vasca, como actividad social, también cumple funciones económicas y culturales. Trataremos en las líneas que siguen de destacar que la traducción literaria vasca también forma parte del mercado editorial y, en ese sentido, tiene una función económica específica. Aunque no sea la única motivación de las editoriales, la importancia del beneficio también forma parte del mercado editorial y algunas traducciones se publican con el fin de obtener las mayores ganancias posibles, y este hecho es cada vez más palpable en el proceso de globalización (Sapiro 2014: 95). De todos modos, no debemos olvidar que la traducción vasca vive una situación con problemas inherentes a las lenguas minorizadas: problemas de mercado reducido y de diglosia (Jarillot y Uribarri 2011: 190-198); el cómputo total de vascoparlantes 
asciende a unos 850.000, y el sociólogo Harkaitz Zubiri calcula que son lectores asiduos unos 15.000 o 20.000 (2013: 51-68). Además, la traducción literaria vasca se desarrolla en un contexto social multilingüe y en estructuras administrativas distintas, con todo lo que ello conlleva (Jarillot y Uribarri 2011: 190-198), pues todo ello implica que la traducción vasca esté sujeta al mecenazgo y a las ayudas gubernamentales. Las colecciones "Literatura Unibertsala" (=Literatura Universal) o "Pentsamentuaren Klasikoak" (=Clásicos del Pensamiento), dos colecciones de traducción que han sido y son actualmente fundamentales, son fruto de iniciativas interinstitucionales (el Gobierno Vasco y la asociación EIZIE en el primero de los casos, y la fundación creada por la Universidad del País Vasco, la Universidad de Deusto, las cajas de ahorros de la Comunidad Autónoma Vasca y el banco BBV en el segundo). ${ }^{8}$ Sin el mecenazgo y sin las ayudas de esas entidades sería imposible para las editoriales vascas, en el mercado editorial actual, sustentar ese tipo de colecciones y asegurar condiciones y contratos de traducción justos para los traductores. Por su parte, en párrafos precedentes ya hemos mencionado que la centralidad de la traducción literaria en el campo de la literatura vasca ha sido crucial para el proceso de autonomización profesional de los autores y traductores, aunque como decíamos solo un $10 \%$ de ellos se dedican exclusivamente a la actividad literaria. Nos gustaría añadir a esa idea que las políticas autonómicas de apoyo al libro vasco (Gobierno Vasco, Instituto Vasco Etxepare) han facilitado la autonomía económica de los autores vascos, ya que hay quien afirma que la ayuda económica para las traducciones y, por tanto, sus autotraducciónes han sido más de una vez vías de ingresos económicos para escritores en lengua vasca (Ibarluzea 2015a: 65-68).

Por último, abordaremos la función cultural que cumplen las traducciones vascas (tanto las traducciones del euskera y al euskera). Según Sapiro, las traducciones pueden influir en los procesos de legitimación, pueden ser herramientas de subversión, pueden ser modos de aparición en la escena internacional para las literaturas nacionales Ilamadas "pequeñas" o pueden ser modos de aumentar el capital simbólico de ciertas editoriales como ya hemos visto en los apartados anteriores; y es que ser traducido a otra lengua es una vía de consagracción para un escritor, $y$, en sentido inverso, traducir a un autor reconocido constituye para un autor una forma de autolegitimarse. Pero, además, a nivel cultural, las traducciones pueden ser fuente de ejercitación de escritura para los autores (2014: 94-96); o tal y como insiste Gémar, la traducción es relevante en tanto en cuanto a su aporte lingüístico (Gémar 1990: 24); Gémar subraya que además de enriquecer la lengua, la traducción ha ayudado a equilibrar el predominio de las grandes lenguas (1990: 249). Bassnett tambien subrayaba la misma idea, y añade que una de las funciones de la traducción es la de ensalzar el estatus de la lengua y de sus variedades, incrementando así el estatus de las lenguas vernáculas (2002: 59). ¿Podríamos hablar, entonces, de una función cultural clara a propósito

\footnotetext{
${ }^{8}$ En el caso de la colección "Literatura Unibertsala", además, durante los últimos años se ha creado una colección paralela compuesta por una selección de números antiguos y descatalogados que han sido revisados y reeditados. Esto es, una vez más, otro ejemplo de la acumulación sistemática selectiva del capital simbólico inherente al campo de la traducción literaria vasca.
} 
de las traducciones literarias al euskera? Lo cierto es que el estado diglósico y de normalización en el que se encuentra la lengua vasca ha antepuesto el aporte linguístico de la traducción a cualquier otro aporte cultural, y los discursos y estudios en cuanto a la función cultural de la traducción se han centrado hasta época reciente en el enriquecimiento estilístico de la lengua. Por ello, abordaremos aquí ante todo ese aspecto.

Como hemos mencionado anteriormente, los escritores vascos contemporáneos no solo aplauden la labor de los traductores vascos por el aporte de nuevos registros lingüísticos y estilísticos; además, algunos de ellos (Kirmen Uribe, por ejemplo) dicen utilizar esas traducciones como herramientas de trabajo en sus propios procesos de creación y escritura (Ibarluzea 2015a: 68). Citemos, al respecto, las palabras del escritor vasco Anjel Lertxundi recogidas y traducidas por Jaka (2005):

Creo que el hecho más importante que ha sucedido en la literatura vasca en los últimos diez años ha sido, de forma indiscutible, el esfuerzo realizado en el ámbito de la traducción. La traducción está construyendo un lenguaje literario; la traducción está abriendo nuevos caminos hacia actitudes distintas, siempre a través de la precisión, puesto que la pluralidad no puede basarse sino en la precisión. (Jaka 2005)

Así lo demuestran las primeras conclusiones de los estudios basados en comparación de corpus de textos literarios traducidos y de textos literarios creados en lengua vasca de investigadores como Etxeberria (2012). Etxeberria caracteriza la lengua vasca traducida con el fin de identificar qué rasgos pudieran estar influyendo en el desarrollo léxico, morfosintáctico y estilístico de la lengua y concluye que la lengua de las traducciones es más ajustada a la norma que la de los textos no traducidos. ${ }^{10}$ Etxeberria constata que en los textos de los traductores se cuidan más las recomendaciones de diccionarios, gramáticas, etc., y que se tiende a rehuir los préstamos cuando existen equivalentes eusquéricos válidos (2014). ${ }^{11}$ Etxeberria ha "detectado también una mayor tendencia a la precisión, el detalle y el matiz en el plano semántico en el euskera de las traducciones", y por último achaca las "similitudes halladas en el uso de los elementos distintivos del euskera" en los textos traducidos al euskera y en los textos literarios creados directamente en euskera a "la alta competencia lingüística y del buen hacer de los traductores contemporáneos". Se puede corroborar, por lo tanto, como la propia Etxeberria dice, que:

El peso de la traducción en el sistema literario de destino se refleja no solo en la influencia que ejerce en la configuración de los cánones literarios o en la importación de nuevos temas, corrientes y estilos, sino también en su carácter de vía de entrada de nuevos modos de expresión y recursos lingüístico-estilís-

\footnotetext{
${ }^{9}$ Recurso online, sin páginación.

10 Recurso online, sin páginación.

11 Conferencia inédita proporcionada por la autora.
} 
ticos. Y es que, durante el proceso de traducción de un texto, el traductor debe hacer frente a los numerosos obstáculos y desafíos que le imponen el texto y la lengua de origen. El traductor no puede o no debe hacer trampas, no puede o no debe eludir las complejidades que le presenta el texto de partida. Las soluciones y los recursos léxicos y estilísticos que propone el traductor en estos trances quedan a disposición del resto de hablantes de la lengua meta, y pasan así a enriquecer el patrimonio de dicha lengua. (Etxeberria 2014)

A los aportes literarios y lingüísticos de la traducción citados anteriormente, debemos añadirles el aporte historiográfico que venimos observando en un análisis (aún sin concluir) de diversas obras que analizan la historia de la literatura vasca, publicados en los siglos xx y xxI. Hemos observado que los textos fundadores de diversos géneros literarios en literatura vasca han sido traducciones, y así se presentan en varias historias de la literatura vasca a lo largo del tiempo. Por lo tanto, no debemos olvidar la función de génesis en lo que a los géneros literarios respecta entre las funciones culturales de la traducción literaria vasca.

\section{Conclusiones generales}

Ruiz Casanova explica que, aunque cabría pensar "que cuanto mayor es el número de traducciones que una lengua incorpora, mayores son sus carencias o menor resulta su capacidad creativa", deberíamos recordar las palabras de Guillén, para quien "las traducciones son pruebas de "la vitalidad de una literatura emergente'" (2000: 523-524). No podemos sino concluir este artículo haciendo nuestra esa idea, tras haber esbozado el proceso de autonomización del subcampo de la traducción literaria vasca. La traducción al euskera ha sido, de alguna manera, un eje fundamental del devenir histórico de los textos vascos, y lo sigue siendo, en cierto modo, teniendo en cuenta que la traducción ocupa un lugar importante entre los títulos literarios publicados anualmente. Puede que sea una evidencia de la debilidad y de la corta trayectoria de la literatura vasca, pero hoy por hoy podemos considerar la literatura traducida como un subcampo literario reconocido social, profesional y académicamente; todo ello es fruto de la autonomización del subcampo de la traducción literaria, de su tejido institucional, profesionalización, especialización editorial y el aumento y la visibilización de las referencias específicas relacionadas con la traducción literaria; han crecido los proyectos de análisis y estudio académico de la traducción, a la vez que la imagen del traductor y la de la literatura traducida se ha vuelto cada vez más positiva; la evolución del subcampo de la traducción literaria ha influido también en la práctica y en el discurso de los escritores vascos contemporáneos (para quienes la traducción ha sido fuente de ingresos en variadas ocasiones), y se ha reflejado en la imagen del traductor como personaje de ficción que ocupa un lugar cada vez más central en la escena ficcional. Podríamos decir que la traducción al euskera ha sido para la literatura vasca una vía de enriquecimiento

${ }^{12}$ Conferencia inédita proporcionada por la autora. 
estilístico y lingüístico, tratándose de una lengua en proceso de normalización y estandarización que aún ha de valerse del mecenazgo institucional para sustentar la circulación de productos literarios en euskera, para apoyar la internacionalización y la visibilización de autores vascos, y para compensar la dependencia del circuito literario estatal y equilibrar el predominio de las grandes lenguas, además de ensalzar su estatus y legitimar sus agentes. Es por ello que, en la mayoría de los casos, la crítica subraya el buen nivel de lengua y la buena legibilidad de las obras traducidas, así como la trayectoria de los traductores. Además, entre todos esos aportes económicos, ideológicos y culturales ha de destacarse, también, la función fundacional de las traducciones en cuanto a varios géneros literarios se refiere, como puede apreciarse en las historias literarias actuales.

\section{OBRAS CITADAS}

Abuín Gonzalez, Anxo, y Tarrío Varela, Anxo (eds.) (2004): Bases metodolóxicas para una historia comparada das literaturas na península Ibérica. Santiago de Compostela, Universidade de Santiago de Compostela.

Arrula, Garazi (2013): <http://elearazi.eus/2013/06/09/irakurle-txokoen-3-e-ak-eleberriaegungoa-eta-etxekoa/> [última visita: 26.01.2016].

Bassnett, Susan (2002): Translation Studies (third edition). Londres / Nueva York, Routledge.

Behinola (2009): <http://http//www.galtzagorri.eus/behinola/dokumentuak/hitz-etapitz-5.pdf> [última visita: 23.05.2016].

Boltanski, Luc (1975): "La constitution du champ de la bande dessinée", Actes de la recherche en sciences sociales, vol. 1, n. ${ }^{0} 1-1$, pp. 37-59.

Bourdieu, Pierre (1984): "The Market of Symbolic Goods". En: The Field of Cultural Production: Essays on Art and Literature. Nueva York, Columbia University Press, pp. 113-144.

_ (1991): "Le Champ littéraire", Actes de la recherche en siences sociales, vol. 89, pp. 3-46. (2013): "Séminaires sur le concept de champ, 1972-1975", Actes de la recherche en sciences sociales, vol. 200, pp. 4-37.

Cabo Aseguinolaza, Fernando (2012): Historia de la literatura española. 9. El lugar de la literatura española. Barcelona, Crítica.

Casanova, Pascale (2004): The World Republic of Letters. Trad. M. B. DeBevoise. Harvard, MA, Harvard University Press.

Deleuze, Gilles, y Guattari, Félix (1975): Kafka: pour une littérature mineure. París, Minuit.

Delgado, Luisa Elena (2014): La nación singular. Fantasías de la normalidad democrática española (1996-2011). Madrid, Siglo xxı.

D'hulst, Lieven (1995): "Pour une historiographie des theories de la traduction: questions de méthode", TTR: traduction, terminologie, rédaction, vol. 8, n. ${ }^{\circ}$ 1, pp. 13-33.

(2013): "La traducción y su papel en las literaturas europeas: algunas preguntas y respuestas". En: C. Domínguez (ed.): Literatura europea comparada. Madrid, Arco Libros, pp. 387-400.

Domínguez, César (2010): "Historiography and the geo-literary imaginary: The Iberian Peninsula: Between Lebensraum and espace vécu". En: Fernando Cabo Aseguinolaza, 
Anxo Abuín González y César Domínguez (eds.): A Comparative History of Literatures in the Iberian Peninsula, volume I. Ámsterdam/Filadelfia, John Benjamins B. V., pp. 53-132.

Etxeberria, Isabel (2012): "Euskarara itzulitako literatur testuen hizkuntza-ezaugarriak eta euskaraz sortutakoenak konparatzeko metodologia-proposamen bat". En: Fernando Garcia Murga y Nerea Madariaga Pisano (eds.): Hitzen artean: Axun Aierbe Gogoan. Udako Euskal Unibertsitatea, pp. 153-174.

- (2014): "Pana y terciopelo en la literatura vasca traducida y no traducida. Aspectos lingüístico-estilísticos resultantes de la comparación de dos corpus". Conferencia inédita, I Coloquio Internacional Hermeneus, Universidad de Valladolid, Soria.

Gémar, Jean Claude (1990): "La traduction est-elle civilisatrice? Fonctions de la traduction et degrés de civilisation", Meta, vol. 35, n. ${ }^{\circ}$ 1, pp. $247-257$.

Heilbron, Joahan, y Sapiro, Gisèle (2002): "La traduction littéraire, un objet sociologique", Actes de la recherche en siences sociales, vol. 144, pp. 3-5.

Ibarluzea, Miren (2011): Euskal itzulpenaren kritika. Azterketa baterako oinarriak eta aplikazio praktikoa. Bilbao, Labayru Ikastegia eta Zornotzako Udala.

_ (2014): "Literatura Unibertsala bildumako hitzaurreen azterketa", Euskera, vol. 58 (II), pp. 687-701.

(2015a): "The Translation Habitus of Contemporary Basque Writers", Estudios de traducción, n. 5, pp. 59-75.

— (2015b): "La Autonomización del Campo de la Traducción Literaria Vasca", Lenguas en Contexto, n. ${ }^{\circ} 12$, pp. 37-45.

Jaka, Aiora (2005): "Translating Basque Literature", Transcript, n. ${ }^{\circ} 20$. Disponible en <http:// http//www.transcript-review.org/en/issue/transcript-20-basque/translating-basque-literature> [última visita: 26.01.1016].

- (2012): Itzulpenari buruzko gogoeta eta itzulpen-praktika Joseba Sarrionandiaren lanetan. Bilbao, Euskaltzaindia.

Jarillot, Cristina, y Uribarri, Ibon (2011): "Politiques de la traduction dans un environnement multilingüe: le cas basque". En: E. Dampiere, A. Melzger e I. Poulin (eds.): Traduction et partages: que pensons-nous devoir transmetre. Burdeos, Université Michel Montaigne, pp. 190-198.

Lasagabaster, Jesús María (2002): Las literaturas de los vascos. Bilbao, Universidad de Deusto.

_ (2007): "Sobre la historia de la literatura vasca: diagnóstico y perspectivas", ASJU, vol. XLI, n. ${ }^{\circ} 1$, pp. 237-248.

Manterola Agirrezabalaga, Elizabete (2014): La literatura vasca traducida. Berna, Peter Lang. Martí Monterde, Antoni (2013): "Interliterariness and the Literary Field: Catalan Literature and Literatures in Catalonia". En: Joan Ramon Resina (ed.): Iberian Modalities. Liverpool, Liverpool University Press, pp. 62-80.

Mendiguren, Xabier (1993): "Euskal itzulpenaren garapena", Senez, vol. 14, pp. 11-32.

Munday, Jeremy (2008): Introducing Translation Studies. Theories and applications (2nd ed.). Londres / Nueva York, Routledge.

Olaziregi, Mari Jose (2005): Waking the Hedgehog. The Literary Universe of Bernardo Atxaga. Reno, Center for Basque Studies / University of Nevada. 
(ed.) (2012): Basque Literary History. Reno, Center for Basque Studies / University of Nevada.

Rubio Tobar, Joaquín (2013): Literatura, Historia y Traducción. Madrid, Ediciones de La Discreta.

Ruiz Casanova, José Francisco (2000): Aproximación a una historia de la traducción en España. Madrid, Cátedra.

Santana, Mario (2009): "On Visible and Invisible Languages: Bernardo Atxaga's Soinujolearen semea in Translation". En: Mari Jose Olaziregi (ed.): Writers in Between Languages: Minority Literatures in the Global Scene. Reno, Center for Basque Studies / University of Nevada, pp. 213-230.

- (2012): "Los mercados de las literaturas en España: la producción literaria", Revista de Alces $x$ XI, n. ${ }^{\circ} 0$, pp. 231-251.

— (2015): "Translation and Literatures in Spain, 2003-2012", 1611 Revista de Historia de la Traducción, vol. 9. Disponible en <http://ddd.uab.cat/pub/1611/1611_a2015n9/1611_ a2015n9a4/santana.htm> [última visita: 26.01.2016].

Sapiro, Gisèle (2010): "L'autonomie de la littérature en question". En Jean-Pierre Martin (dir.): Bourdieu et la littérature. Nantes, Éditions Cécile Defaut, pp. 45-61.

(2014): La sociologie de la littérature. París, Éditions La Decouverte.

Venuti, Lawrence (2013): Translation Changes Everything, Theory and Practice. Londres / Nueva York, Routledge.

Vizcarra, Fernando (2002): "Premisas y coneptos básicos en la sociología de Pierre Bourdieu", Estudios sobre las Culturas Contemporáneas, vol. vIII, n. 16, pp. 55-68.

Wolf, Michaela (2007): "Introduction. The emergence of a Sociology of Translation". En Michaela Wolf y Alexandra Fukari (eds.): Constructing a Sociology of Translation. Ámsterdam/Filadelfia, John Benjamins Publishing Company, pp. 1-36.

Woodsworth, Judith (2009): "History of translation". En: Mona Baker (ed.): Routledge Enciclopedia of Translation Studies. Londres / Nueva York, Routledge, pp. 100-105.

Zubillaga, Naroa (2014): "Alemanetik euskaratutako haur- eta gazte-literatura. Tesiaren ideia nagusiak", Senez, vol. 45. Disponible en <http://http//www.eizie.eus/Argitalpenak/Senez/20141028/11zubillaga/senez45_zubillaga.pdf> [última visita: 26.01.1016].

Zubiri, Harkaitz (2013): "Euskal literaturaren irakurleak zenbat eta nolakoak diren aztergai. Soziolinguistikako datuetatik eta irakurketa-ohiturei buruzko ikerketetatik abiatuta", Uztaro, n. ${ }^{\circ} 87$, pp. 51-68. 